\title{
Association of Environmental Toxic Metals with High Sensitivity C-Reactive Protein: A Cross-Sectional Study
}

\author{
Humairat H. Rahman'1, Danielle Niemann², Andrew Bugajski ${ }^{3}$ \\ ${ }^{1}$ New Mexico State University, Las Cruces, NM, USA \\ ${ }^{2}$ Burrell College of Osteopathic Medicine, Las Cruces, NM, USA \\ ${ }^{3}$ College of Nursing, University of South Florida, Tampa, FL, USA \\ Email: hrahman@nmsu.edu,danielle.niemann@burrell.edu, andrew.bugajski@mylrh.org
}

How to cite this paper: Rahman, H.H., Niemann, D. and Bugajski, A. (2021) Association of Environmental Toxic Metals with High Sensitivity C-Reactive Protein: A CrossSectional Study. Occupational Diseases and Environmental Medicine, 9, 173-184. https://doi.org/10.4236/odem.2021.94013

Received: September 5, 2021

Accepted: October 5, 2021

Published: October 8, 2021

Copyright $\odot 2021$ by author(s) and Scientific Research Publishing Inc. This work is licensed under the Creative Commons Attribution International License (CC BY 4.0).

http://creativecommons.org/licenses/by/4.0/

\begin{abstract}
Objective: Metals including arsenic, lead, mercury, and cadmium are toxic and can increase cardiovascular disease risk. High-sensitivity C-reactive protein (hs-CRP) is a biomarker for inflammation and cardiovascular risk. This study will evaluate the association between urinary speciated arsenic, cadmium, lead, and mercury and blood values of hs-CRP in the United States adult population. Methods: A cross-sectional study using the 2015-2016 NHANES dataset, conducting multivariate linear regressions to analyze selected urinary metals and links with serum hs-CRP. Results: The sample consisted of 780 adults. In adjusted models, arsenocholine was found to be protective of inflammation, whereas aresnous acid, which is an inorganic, toxic type of arsenic acid, was positively associated with hs-CRP $(b=2.53)$. Conclusion: Urinary arsenous acid is a significant predictor of hs-CRP which is a biomarker for CVD.
\end{abstract}

\section{Keywords}

Hs-CRP, Arsenous Acid, Lead, Cardiovascular Disease, NHANES

\section{Introduction}

Arsenic is a human carcinogen linked to bladder, skin, and lung cancers, skin lesions, and depression [1] [2]. Arsenic has also been associated with arsenicrelated cardiovascular disease suggesting that arsenic exposure leads to thrombosis and inflammation [3]. Drinking water with arsenic concentrations greater than $10 \mu \mathrm{g} / \mathrm{L}$ has been linked to an increased risk of fatal and non-fatal coronary heart disease (CHD), cardiovascular disease (CVD), carotid atherosclerosis, 
hypertension, CHD mortality, and CVD mortality [4]. In addition to contaminated water, arsenic exposure can occur through foods including rice and apple juice [1].

In addition, exposure to lead, mercury, and cadmium has resulted in negative health effects in humans. Exposure to lead has resulted in positive associations with CVD, CHD, stroke mortality, and peripheral arterial disease. Several studies have identified a dose-response relationship between lead exposure and blood pressure [5]. An inverse relationship between glomerular filtration rate (GFR) and blood lead has been reported, suggesting a lead induced reduction in renal function, playing a role in hypertension [6]. Furthermore, mercury exposure can be in the form of elemental, inorganic, and organic forms. Dental amalgams used in dental procedures are the most common elemental exposure. Inorganic mercury typically is produced in the body through the conversion of other forms, while organic mercury is usually from fish, sea mammals, and thimerosal vaccines. Mercury has been linked to dyslipidemia, thrombosis, endothelial dysfunction, vascular smooth muscle proliferation and migration, immune dysfunction, and mitochondrial dysfunction [7]. Lastly, cadmium has been shown to affect vasopressor-induced reactivity and stress-strain features of the blood vessel wall, leading to hypertension [8]. Cadmium exposure is uncommon but can occur through consumption of polluted water or chronic inhalation from cigarettes [7]. Cadmium has been associated with hypertension, proteinuria, emphysema, osteomalacia, and cancer [9].

C-reactive protein (CRP) is an acute phase protein that can be elevated in response to inflammatory cytokines, infection, and trauma, and increases with age [10] [11]. CRP is involved in the immunologic process that causes vascular remodeling and plaque deposition, and is associated with increased cardiovascular risk [12]. Serum CRP can be measured using standard and high sensitivity c-reactive protein (hs-CRP), which are both used in clinical practice. However, the standard assay is not sensitive enough to measure low grade inflammation, whereas hs-CRP can detect a low grade inflammatory state [3] [10]. Some studies have also proposed hs-CRP as a predictor of all-cause mortality [10].

Studies have shown that arsenic exposure increases oxidative stress, inflammation, and atherosclerotic lesion formation [13]. In one study, exposure to environmentally relevant levels of arsenic resulted in elevated CRP secretion and expression in humans. In those exposed to arsenic through groundwater contamination, sputum samples contained an increased number of alveolar macrophages and inflammatory cells in addition to CRP. Drinking arsenic contaminated groundwater was found to cause pulmonary and systemic inflammation, which generates ROS in the airways [14]. Furthermore, in lead exposure, metal mediated formation of free radicals can increase lipid peroxidation. Similar to arsenic, lead promotes the production of ROS, which then triggers a cycle of oxidative stress and inflammation in target tissues [6]. In studies analyzing mercury exposure, the level of hs-CRP was significantly positively correlated with blood 
pressure and blood mercury [15]. Blood cadmium levels were also positively associated with inflammatory risk and hs-CRP as well as urinary cadmium [16].

In animal studies, an association was established between arsenic contamination and atherosclerosis in rats. Rats that were fed arsenic contaminated water and a high-fat diet were seen to have increased hs-CRP [17]. Furthermore, treatment of mice with sodium arsenite in drinking water for 6 months resulted in higher levels of CRP in the liver and kidneys. It is suggested that arsenic exposure increases CRP, which activates further pathways contributing to metabolic syndrome and cardiovascular disease [11]. In studies investigating the effects of lead on rats, treatment with lead resulted in increased blood lead levels, blood pressure, and aortic ring contractile response to phenylephrine. Increased blood lead concentrations resulted in reduced nitric oxide bioavailability, increased ROS production, increased participation of COX-derived contractile prostanoids, and increased rennin-angiotensin system activity [18]. In rabbits exposed to mercury vapor, thrombosis in small and medium caliber arteries, focal necrosis with thickening of the endocardium, papillary muscles and valves, and endothelial proliferation with inflammation and fibrosis of the ascending aorta was noted [19]. Animal studies have also confirmed that cadmium can cause atherosclerosis [20].

\section{Knowledge Gap}

Few studies have analyzed the association between urinary speciated arsenic and hs-CRP in humans. Animal studies suggest that these metals may increase hs-CRP in humans [17]. The purpose of this study is to use the National Health and Nutrition Examination Survey (NHANES) dataset to explore if there is an association between arsenic, lead, mercury, and cadmium and hs-CRP in the United States (US) population. We expect that hs-CRP levels will be increased based on heavy metal exposure due to the inflammatory properties of toxic metals.

\section{Methods}

\subsection{Study Population}

The 2015-2016 NHANES dataset was used for this study as it is the most recent data published by the CDC at this time. NHANES is a national study throughout the US to determine the health and nutritional status of children and adults [1]. Although blood lead and mercury are available in the NHANES dataset and are more reliable markers for human exposure, this study's objective was to measure urinary metal concentrations-in terms of feasibility of collection and future research implications, urine is often easier to collect and thus further supports our decision to use urine concentrations. Urinary arsenic, lead, and cadmium samples were collected from participants 18 years and older who met the regular one-third subsample selection criteria. In addition, to oversample adult smokers, those not in the one-third subsample who smoked at least 100 cigarettes in their 
lifetime were included [21] [22]. Urinary mercury samples collected for the one-third subsample included participants aged 6 years and older [23]. Hs-CRP samples were collected in participants aged 1 year and older [24]. The inclusion criteria for our study included all participants aged $\geq 18$ years that were included in following 2015-2016 NHANES datasets: "Speciated Arsenics-Urine-Special Sample (UASS_I)", the urinary lead variable URXUPB and urinary cadmium variable URXUCD in "Metals-Urine-Special Sample (UMS_I)", "MercuryUrine (UHG_I)" and "High-Sensitivity C-Reactive Protein (hs-CRP) (HSCRP_I)." Only those with detectable values for our outcome, hs-CRP, were included in efforts to minimize missing data in all analyses. For demographic variables used, the 2015-2016 "Demographic Variables and Sample Weights (DEMO_I)" and "Alcohol Use (ALQ_I)" datasets were used. The CDC approved the NHANES study.

\subsection{Urinary Metals Assessment}

Laboratory methods used by NHANES in the collection and analysis of urinary arsenic, lead, cadmium, and mercury samples can be found in the "ArsenicsSpeciated-Urine Laboratory Procedure Manual", "Urinary Metals and Total Arsenic Laboratory Procedure Manual", and the "Iodine and Mercury, Urine Lab Procedure Manual" respectively. All urinary metals samples were collected at Mobile Examination Centers (MECs) and were processed, stored, and shipped to the Division of Laboratory Sciences, National Center for Environmental Health, Centers for Disease Control and Prevention, Atlanta, GA for analysis [21] [22] [23]. Speciated arsenic was composed of six different arsenic compounds: urinary arsenic acid, arsenous acid, arsenobetaine, arsenocholine, dimethylarsinic acid (DMA), and monomethylarsonic acid (MMA).

Each speciated arsenic was first dichotomized as "0" indicating the lab value was below the limit of detection, and "1" indicating the lab value was at or above the limit of detection. Then, those values that were at or above the limit of detection were split into two equal groups by assessing each speciated arsenic's median detectable lab value. In total, each speciated arsenic could be coded as "0", "1" or " 2 ", where " 0 " indicated below the limit of detection, "1" indicated it was detectable but in the lower half of all detectable samples' values, and "2" indicated it was detectable but in the upper half of all detectable sample values. This technique also maximizes available data. Due to large amounts of participants having missing or lab data below the detectable limit, predictive techniques would result in abysmally small useable sample sizes. Given the exploratory nature of this study, complex methods of noise reduction, general estimating equations (GEE), or nested models were not chosen; the purpose was to explore relationships thus warranted a grouping of variables that supports associations, not paramount/precise levels of measurement.

Of note, urinary arsenic acid was excluded as a variable from these analyses as there were only 22 participants that were above the detectable limit, which 
would have adversely affected accuracy and generalizability of our analyses. Thus, for final analyses, there were only 5 speciated arsenics analyzed in multivariate regression analyses. The lower limit of detection (LLOD) for speciated arsenic was: $0.12 \mu \mathrm{g} / \mathrm{L}$ for urinary arsenous acid, $0.79 \mu \mathrm{g} / \mathrm{L}$ for urinary arsenic acid, $1.16 \mu \mathrm{g} / \mathrm{L}$ for urinary arsenobetaine, $0.11 \mu \mathrm{g} / \mathrm{L}$ for urinary arsenocholine, $1.91 \mu \mathrm{g} / \mathrm{L}$ for urinary DMA, and $0.20 \mu \mathrm{g} / \mathrm{L}$ for urinary MMA [21]. The LLOD for urinary lead was $0.030 \mu \mathrm{g} / \mathrm{L}$. The LLOD for urinary cadmium was $0.036 \mu \mathrm{g} / \mathrm{L}$ [22]. The LLOD for urinary mercury was $0.13 \mu \mathrm{g} / \mathrm{L}$ [23].

\subsection{High Sensitivity C-Reactive Protein Assessment}

Laboratory methods used by NHANES in the collection and analysis of hs-CRP can be found in the "High Sensitivity C-Reactive Protein" laboratory method file. Specimens were collected at MECs, and then processed, stored, and shipped to the Collaborative Laboratory Services, Ottumwa, Iowa for analysis. The LLOD for hs-CRP was $0.11 \mathrm{mg} / \mathrm{L}$ [24].

\subsection{Statistical Analysis}

All data analyzed was derived from NHANES 2015-2016. NHANES analytic principles were followed, which accounts for variations in detectable limits of lab values and the effect of sample/survey design via sample weights. Descriptive statistics in the form of mean, standard deviation, frequencies, and percentages were calculated based upon the level of measurement. Multivariate linear regressions were then conducted in two steps to explore the effect of speciated arsenics, cadmium, lead, and mercury on high-sensitivity CRP. In the first model, all metals (speciated arsenics, cadmium, lead, and mercury) were run together without adjusting for covariates. Then, an adjusted model with the covariates of age, gender, race/ethnicity, and smoking status were added to all metals in the unadjusted model. Beta coefficients, 95\% confidence intervals (95\% CI), and p-values were recorded. All analyses were conducted using JMP Pro 14 (SAS Institute Inc., Cary, NC, 1989-2019).

\section{Results}

After selection of variables, the available sample size was 780 participants, with the breakdown shown in Table 1. The sample consisted of 401 (51.4\%) males, with an average age of 49.6 years at screening. The majority of the sample was married (52.3\%), had some college or a college degree (52.2\%) and were white (33.3\%); 19.7\% of the sample was Black, followed by Mexican American (17.4\%), Other Hispanic (14.7\%) and Asian (14.7\%). Unadjusted hs-CRP values averaged $4.41+8.09 \mathrm{mg} / \mathrm{L}$. However, visual inspection clearly alluded to substantial outliers of hs-CRP. After removal of participants $(n=11)$ with hs-CRP values greater than three standard deviations above the mean, the adjusted hs-CRP for the sample was $3.67+4.44$, indicating that the average participant had high above normal systemic inflammation. 
Table 1. Demographic characteristics of the study sample.

\begin{tabular}{lc}
\hline \multicolumn{1}{c}{ Variable } & Frequency/Count (\%) or Mean (SD) \\
\hline Age at screening & $49.6(18.3)$ \\
\hline Gender (Males) & $401(51.4 \%)$ \\
\hline Race/ethnicity & $\mathrm{N}=29$ missing \\
Mexican American & $136(17.4 \%)$ \\
Other Hispanic & $115(14.7 \%)$ \\
White & $260(33.3 \%)$ \\
Black & $154(19.7 \%)$ \\
Asian & $115(14.7 \%)$ \\
\hline Highest level of education & $\mathrm{N}=29 \mathrm{missing}$ \\
Less than GED or High School Diploma & $173(23.0 \%)$ \\
GED or High School Diploma & $186(24.8 \%)$ \\
Some College or College Degree & $392(52.2 \%)$ \\
\hline Family poverty-to-income ratio & $2.4(1.6)$ \\
\hline Marital Status & $\mathrm{N}=29 \mathrm{missing}$ \\
Married & $393(52.3 \%)$ \\
Widowed & $54(7.2 \%)$ \\
Divorced & $90(12.0 \%)$ \\
Separated & $20(2.7 \%)$ \\
Never Married & $131(17.4 \%)$ \\
Living with Partner & $62(8.3 \%)$ \\
\hline BMI & $29.6(6.9)$ \\
\hline
\end{tabular}

Of the study sample, 767 (98.3\%) had a detectable amount of any arsenic or heavy metals. In regards to the speciated arsenics, the proportions of the sample with detectable amounts of each arsenic were as follows: Urinary arsenous (47.8\%), urinary arsenobetaine (50.1\%), urinary arsenocholine (16.0\%), urinary DMA (73.4\%), and urinary MMA (59.4\%).

Table 2 portrays the unadjusted relationships between speciated arsenics, heavy metals and hs-CRP. Overall, the unadjusted model is not significant $F(16,763)=$ $1.56, \mathrm{p}=0.07$. Table 3 portrays the adjusted model between the speciated arsenics, heavy metals, selected demographics and hs-CRP; $F(24,316)=1.85, \mathrm{p}<0.01$. Of note, those who were in the upper half of detectable values for urinary arsenous $b=2.53[0.88,4.18], \mathrm{p}<0.01$, lower $b=-3.09[-5.28,-0.89], \mathrm{p}<0.01$ or upper half of arsenocholine $b=-3.34[-5.47,-1.22], \mathrm{p}<0.01$, all significantly predicted hs-CRP values. Not depicted in the table, but also being of Other Hispanic origin had a significant association with hs-CRP, $b=3.55[0.25,6.84], \mathrm{p}=0.035$.

\section{Discussion}

Arsenous acid (As III) is a form of inorganic arsenic. Biotransformation of inorganic arsenic involves reduction of As (V) (arsenic acid) to As (III) (arsenous acid), then oxidative methylation to MMA and DMA [25]. Although arsenic acid was not included in our study, the upper half of detectable limits of arsenous acid predicted hs-CRP. Few other studies have been conducted on the association 
Table 2. Unadjusted model and unstandardized beta estimates with $95 \%$ confidence intervals (CI) of the association between arsenic and hs-CRP, NHANES 2015-2016.

\begin{tabular}{|c|c|c|}
\hline Urinary Metal & B $(95 \% \mathrm{CI})$ & P Value \\
\hline $\begin{array}{l}\text { Lower half of detectable limits of Monomethylarsonic } \\
\text { acid }(\mu \mathrm{g} / \mathrm{L})\end{array}$ & $0.13(-0.58,0.84)$ & 0.715 \\
\hline $\begin{array}{l}\text { Upper half of detectable limits of Monomethylarsonic } \\
\text { acid }(\mu \mathrm{g} / \mathrm{L})\end{array}$ & $-0.06(-0.93,0.81)$ & 0.889 \\
\hline $\begin{array}{l}\text { Lower half of detectable limits of Dimethylarsinic acid } \\
(\mu \mathrm{g} / \mathrm{L})\end{array}$ & $-0.03(-0.77,0.71)$ & 0.931 \\
\hline $\begin{array}{l}\text { Upper half of detectable limits of Dimethylarsinic acid } \\
(\mu \mathrm{g} / \mathrm{L})\end{array}$ & $-0.19(-1.11,0.74)$ & 0.685 \\
\hline Lower half of detectable limits of Arsenocholine $(\mu \mathrm{g} / \mathrm{L})$ & $-0.97(-2.10,0.14)$ & 0.088 \\
\hline $\begin{array}{l}\text { Upper half of detectable limits of Arsenocholine } \\
(\mu \mathrm{g} / \mathrm{L})\end{array}$ & $-1.23(-2.25,-0.21)$ & 0.017 \\
\hline $\begin{array}{l}\text { Lower half of detectable limits of Arsenobetaine acid } \\
(\mu \mathrm{g} / \mathrm{L})\end{array}$ & $-0.01(-0.69,0.67)$ & 0.967 \\
\hline $\begin{array}{l}\text { Upper half of detectable limits of Arsenobetaine acid } \\
(\mu \mathrm{g} / \mathrm{L})\end{array}$ & $0.20(-0.53,0.93)$ & 0.599 \\
\hline Lower half of detectable limits of Arsenous acid $(\mu \mathrm{g} / \mathrm{L})$ & $0.52(-0.20,1.24)$ & 0.157 \\
\hline $\begin{array}{l}\text { Upper half of detectable limits of Arsenous acid } \\
(\mu \mathrm{g} / \mathrm{L})\end{array}$ & $1.34(0.51,2.16)$ & 0.002 \\
\hline Lower half of detectable limits of Cadmium $(\mu \mathrm{g} / \mathrm{L})$ & $-0.83(-2.27,0.61)$ & 0.258 \\
\hline Upper half of detectable limits of Cadmium $(\mu \mathrm{g} / \mathrm{L})$ & $-0.71-2.22,0.80)$ & 0.357 \\
\hline Lower half of detectable limits of Mercury $(\mu \mathrm{g} / \mathrm{L})$ & $0.31(-0.34,0.96)$ & 0.350 \\
\hline Upper half of detectable limits of Mercury $(\mu \mathrm{g} / \mathrm{L})$ & $0.47(-0.22,1.16)$ & 0.181 \\
\hline Lower half of detectable limits of Lead $(\mu \mathrm{g} / \mathrm{L})$ & $1.33(-0.51,3.18)$ & 0.156 \\
\hline Upper half of detectable limits of Lead $(\mu \mathrm{g} / \mathrm{L})$ & $1.66(-0.26,3.58)$ & 0.091 \\
\hline
\end{tabular}

Note: reference group for each variable are those with values coded as: below detectable limit.

Table 3. Adjusted model and unstandardized beta estimates with $95 \%$ confidence intervals (CI) of the association between arsenic and hs-CRP, NHANES 2015-2016.

\begin{tabular}{lcc}
\hline \multicolumn{1}{c}{ Urinary Metal } & B $(95 \% \mathrm{CI})$ & P Value \\
\hline $\begin{array}{l}\text { Lower half of detectable limits of Monomethylarsonic } \\
\text { acid }(\mu \mathrm{g} / \mathrm{L})\end{array}$ & $-0.48(-1.89,0.92)$ & 0.503 \\
$\begin{array}{l}\text { Upper half of detectable limits of Monomethylarsonic } \\
\text { acid }(\mu \mathrm{g} / \mathrm{L})\end{array}$ & $0.01(-1.69,1.72)$ & 0.989 \\
$\begin{array}{l}\text { Lower half of detectable limits of Dimethylarsinic acid } \\
(\mu \mathrm{g} / \mathrm{L})\end{array}$ & $0.21(-1.24,1.66)$ & 0.773 \\
$\begin{array}{l}\text { Upper half of detectable limits of Dimethylarsinic acid } \\
(\mu \mathrm{g} / \mathrm{L})\end{array}$ & $-0.82(-2.79,1.14)$ & 0.409 \\
$\begin{array}{l}\text { Lower half of detectable limits of Arsenocholine } \\
(\mu \mathrm{g} / \mathrm{L})\end{array}$ & $\mathbf{- 3 . 0 9 ( - 5 . 2 8 , - 0 . 8 9 )}$ & $\mathbf{0}$ \\
\hline
\end{tabular}




\section{Continued}

Upper half of detectable limits of Arsenocholine $(\mu \mathrm{g} / \mathrm{L})$

Lower half of detectable limits of Arsenobetaine acid $(\mu \mathrm{g} / \mathrm{L})$

Upper half of detectable limits of Arsenobetaine acid $(\mu \mathrm{g} / \mathrm{L})$

Lower half of detectable limits of Arsenous acid ( $\mu \mathrm{g} / \mathrm{L})$

Upper half of detectable limits of Arsenous acid $(\mu \mathrm{g} / \mathrm{L})$

Lower half of detectable limits of Cadmium $(\mu \mathrm{g} / \mathrm{L})$

Upper half of detectable limits of Cadmium $(\mu \mathrm{g} / \mathrm{L})$

Lower half of detectable limits of Mercury $(\mu \mathrm{g} / \mathrm{L})$

Upper half of detectable limits of Mercury $(\mu \mathrm{g} / \mathrm{L})$

Lower half of detectable limits of Lead $(\mu \mathrm{g} / \mathrm{L})$

Upper half of detectable limits of Lead $(\mu \mathrm{g} / \mathrm{L})$
$-3.34(-5.47,-1.22) \quad 0.002$

$-0.43(-1.81,0.95) \quad 0.541$

$0.43(-1.14,2.00) \quad 0.592$

$0.611(-0.78,2.00) \quad 0.388$

$2.53(0.88,4.18) \quad 0.003$

$-1.19(-5.02,2.64) \quad 0.542$

$-1.21(-5.18,2.77) \quad 0.551$

$1.09(-0.17,2.35) \quad 0.092$

$0.88(-0.48,2.23) \quad 0.206$

$3.01(-1.79,7.80) \quad 0.219$

$3.67(-1.27,8.63) \quad 0.145$

*Adjusted for age, gender, race/ethnicity, and smoking status. Note: Reference group for each variable are those with values coded as: Below detectable limit.

between speciated arsenic and hs-CRP. Yang et al. used toenail arsenic levels and found no significant association with hs-CRP [26]. Moon et al. found no association between urine arsenic and plasma hs-CRP or other variables associated with CHD including plasminogen activator inhibitor-1 (PAI-1) and fibrinogen [3]. However, Karim et al. determined that subjects in arsenic-endemic areas had increased CRP compared to non-endemic subjects when measuring arsenic exposure by water, hair, and nail arsenic concentrations [27].

Arsenocholine is a form of organic arsenic; humans ingest it primarily through seafood and excrete it in their urine. Arsenocholine comes from the breakdown of eukaryotic organisms at the bottom of the aquatic food chain and is then oxidized to arsenobetaine. Arsenocholine and arsenobetaine are exceptions to the severe cytotoxicity of inorganic forms of arsenic [28]. Organic arsenic, including arsenobetaine, arsenocholine, and arsenosugars, is considered non-toxic to humans [2]. Seafood is the main source of organic arsenic. Fish and shellfish have high tissue levels of organic, non-toxic arsenicals. In humans, organic arsenic is excreted through the kidneys, contributing to total urine arsenic, but is not toxic to the body [29]. In our study both the upper and lower half of detectable limits of arsenocholine in the adjusted and the upper half of detectable limits in the unadjusted models were negatively associated with hs-CRP-thus implicating that there is a protective effect of arsenocholine in regard to systemic inflammation measured by hs-CRP.

Hs-CRP is a biomarker related to cardiovascular disease risk in addition to hypertension, hyperglycemia, and serum lipid levels [30]. In addition to hs-CRP, several studies have linked arsenic to cardiovascular disease using other markers. 
In a review of 31 studies, Moon et al. determined that an association between low-moderate arsenic levels and cardiovascular disease was inconclusive, but there was evidence of cardiovascular disease with high-chronic arsenic exposure [31]. Chen et al. determined a dose-response relationship between arsenic exposure from well water and mortality from ischemic heart disease [32].

Other metals in our study, including lead, mercury, and cadmium, were not statistically significantly predictive of hs-CRP. Sirivarasai et al. found an association between blood lead and hs-CRP as well as lead and increased systolic blood pressure [33]. However, Lin et al. found no association between urinary lead and hs-CRP [34]. Our study found no association between urinary lead and hs-CRP in the unadjusted or adjusted models. In addition, Pollack et al. found no association between blood lead, cadmium, or mercury and hs-CRP [35]. We also did not find any association between mercury and cadmium and hs-CRP, however, our study used urinary metal levels rather than blood concentrations. Few studies have been conducted using urinary mercury and cadmium in relation to cardiovascular disease. This is the first study to analyze both urinary mercury and cadmium with hs-CRP and determine there was no significance between mercury and cadmium and risk factors for CVD.

\section{Strengths and Limitations}

This is the first study to use both organic and inorganic speciated arsenic, urinary mercury, and urinary cadmium and hs-CRP. Prior studies did not report the breakdown of arsenic forms to determine which type of arsenic may be responsible for inflammation and chronic disease. This study also used a large dataset that is representative of the US population. Limitations to our study include the lack of adjustment for seafood consumption-although this was possible to control for in the NHANES dataset, after filtering for those who had data for this variable resulted in an abysmally reduced sample size, thus warranting exclusion for our analyses. Our study only used the marker hs-CRP so we can only generalize our results to hs-CRP rather than cardiovascular disease, atherosclerosis, or other chronic diseases. Also, as previously mentioned, our decision to code metal exposure into " 0,1 , or 2 " in terms of concentration is not paramount, however, it suffices for the exploratory nature of this study. Lastly, age, gender, race/ethnicity, highest level of education, family poverty-to-income-ratio, marital status, and BMI were the only demographic factors included in our demographic table (Table 1). Further information about clinical conditions or other clinical markers that could be linked to cardiovascular disease were not included.

\section{Conclusion}

Our study found an association between hs-CRP and the upper half of detectable limits of arsenous acid, and both the upper and lower half of detectable limits of arsenocholine in the adjusted model. Hs-CRP is a marker for inflammation as well as cardiovascular disease, suggesting that arsenous acid, an inorganic form of arsenic, may be linked to cardiovascular disease. The association between 
hs-CRP and arsenocholine is most likely due to seafood consumption. More studies analyzing speciated arsenic and hs-CRP are needed to confirm our findings and to determine how each type of arsenic is linked to cardiovascular disease.

\section{Conflicts of Interest}

The authors declare no conflicts of interest regarding the publication of this paper.

\section{References}

[1] Rahman, H.H., Niemann, D. and Singh, D. (2020) Arsenic Exposure and Association with Hepatitis E IgG Antibodies. Occupational and Environmental Medicine, 8, 111-122. https://doi.org/10.4236/odem.2020.83009

[2] Rahman, H.H., Yusuf, K.K., Niemann, D. and Dipon, S.R. (2020) Urinary Speciated Arsenic and Depression among US Adults. Environmental Science and Pollution Research, 27, 23048-23053. https://doi.org/10.1007/s11356-020-08858-2

[3] Moon, K.A., Navas-Acien, A., Grau-Pérez, M., Francesconi, K.A., Goessler, W., Guallar, E., Umans, J.G., Best, L.G. and Newman, J.D. (2017) Low-Moderate Urine Arsenic and Biomarkers of Thrombosis and Inflammation in the Strong Heart Study. PLoS ONE, 12, e0182435. https://doi.org/10.1371/journal.pone.0182435

[4] Xu, L., Mondal, D. and Polya, D.A. (2020) Positive Association of Cardiovascular Disease (CVD) with Chronic Exposure to Drinking Water Arsenic (As) at Concentrations below the WHO Provisional Guideline Value: A Systematic Review and Meta-Analysis. International Journal of Environmental Research and Public Health, 17, 2536. https://doi.org/10.3390/ijerph17072536

[5] Navas-Acien, A., Guallar, E., Silbergeld, E.K. and Rothenberg, S.J. (2007) Lead Exposure and Cardiovascular Disease-A Systematic Review. Environmental Health Perspectives, 115, 472-482. https://doi.org/10.1289/ehp.9785

[6] Sharma, P. and Purohit, P. (2014) Lead Exposure Exacerbates Cardiovascular Risk. IJCB, 29, 117-118. https://doi.org/10.1007/s12291-014-0430-8

[7] Houston, M.C. (2007) The Role of Mercury and Cadmium Heavy Metals in Vascular Disease, Hypertension, Coronary Heart Disease, and Myocardial Infarction. Alternative Therapies in Health and Medicine, 13, S128-S133.

[8] Spieker, C., Zidek, W. and Zumkley, H. (1987) Cadmium and Hypertension. Nephron, 47, 34-36. https://doi.org/10.1159/000184550

[9] Hallenbeck, W.H. (1984) Human Health Effects of Exposure to Cadmium. Experientia, 40, 136-142. https://doi.org/10.1007/BF01963576

[10] Li, Y., Zhong, X., Cheng, G., Zhao, C., Zhang, L., Hong, Y., Wan, Q., He, R. and Wang, Z. (2017) Hs-CRP and All-Cause, Cardiovascular, and Cancer Mortality Risk: A Meta-Analysis. Atherosclerosis, 259, 75-82. https://doi.org/10.1016/j.atherosclerosis.2017.02.003

[11] Druwe, I.L., Sollome, J.J., Sanchez-Soria, P., Hardwick, R.N., Camenisch, T.D. and Vaillancourt, R.R. (2012) Arsenite Activates NF $\kappa$ B through Induction of C-Reactive Protein. Toxicology and Applied Pharmacology, 261, 263-270.

https://doi.org/10.1016/j.taap.2012.04.005

[12] Yousuf, O., Mohanty, B.D., Martin, S.S., Joshi, P.H., Blaha, M.J., Nasir, K., Blumenthal, R.S. and Budoff, M.J. (2013) High-Sensitivity C-Reactive Protein and Cardiovascular Disease: A Resolute Belief or an Elusive Link? Journal of the American 
College of Cardiology, 62, 397-408.

[13] Srivastava, S., Vladykovskaya, E.N., Haberzettl, P., Sithu, S.D., D’Souza, S.E. and States, J.C. (2009) Arsenic Exacerbates Atherosclerotic Lesion Formation and Inflammation in ApoE-/-mice. Toxicology and Applied Pharmacology, 241, 90-100. https://doi.org/10.1016/j.taap.2009.08.004

[14] Sinha, D., Mukherjee, B., Bindhani, B., Dutta, K., Saha, H., Prasad, P. and Ray, M. (2014) Chronic Low Level Arsenic Exposure Inflicts Pulmonary and Systemic Inflammation. Science World Journal of Cancer Science and Therapy, 6, 62-69.

[15] Lim, S., Ha, M., Hong, Y., Leem, J., Sakong, J., Kim, S., Lee, C., Kang, D., Oh, S. and Kwon, H. (2008) Mercury Effect on Blood Pressure through hs-CRP in Children. Epidemiology, 19, S236.

[16] Olszowski, T., Baranowska-Bosiacka, I., Gutowska, I. and Chlubek, D. (2012) ProInflammatory Properties of Cadmium. Acta Biochimica Polonica, 59, 475-482. https://doi.org/10.18388/abp.2012_2080

[17] Cheng, T.J., Chuu, J.J., Chang, C.Y., Tsai, W.C., Chen, K.J. and Guo, H.R. (2011) Atherosclerosis Induced by Arsenic in Drinking Water in Rats through Altering Lipid Metabolism. Toxicology and Applied Pharmacology, 256, 146-153. https://doi.org/10.1016/j.taap.2011.08.001

[18] Silveira, E.A., Siman, F.D., de Oliveira Faria, T., Vescovi, M.V., Furieri, L.B., Lizardo, J.H., Stefanon, I., Padilha, A.S. and Vassallo, D.V. (2014) Low-Dose Chronic Lead Exposure Increases Systolic Arterial Pressure and Vascular Reactivity of Rat Aortas. Free Radical Biology \& Medicine, 67, 366-376. https://doi.org/10.1016/j.freeradbiomed.2013.11.021

[19] Wojciechowski, J. and Kowalski, W. (1975) Cardiac and Aortic Lesions in Chronic Experimental Poisoning with Mercury Vapors. Polish Medical Science and History Bulletin, 15, 255-260.

[20] Messner, B. and Bernhard, D. (2010) Cadmium and Cardiovascular Diseases: Cell Biology, Pathophysiology, and Epidemiological Relevance. Biometals, 23, 811-822. https://doi.org/10.1007/s10534-010-9314-4

[21] CDC (2018) Speciated Arsenics-Urine-Special Sample (UASS_I). https://wwwn.cdc.gov/Nchs/Nhanes/2015-2016/UASS_I.htm

[22] CDC (2018) Metals-Urine-Special Sample (UMS_I). https://wwwn.cdc.gov/Nchs/Nhanes/2015-2016/UMS_I.htm

[23] CDC (2018) Mercury-Urine (UHG_I). https://wwwn.cdc.gov/Nchs/Nhanes/2015-2016/UHG_I.htm

[24] CDC (2019) High-Sensitivity C-Reactive Protein (hs-CRP) (HSCRP_I). https://wwwn.cdc.gov/Nchs/Nhanes/2015-2016/HSCRP_I.htm

[25] deCastro, B.R., Caldwell, K.L., Jones, R.L., Blount, B.C., Pan, Y., Ward, C. and Mortensen, M.E. (2014) Dietary Sources of Methylated Arsenic Species in Urine of the United States Population, NHANES 2003-2010. PLOS ONE, 9, e108098.

https://doi.org/10.1371/journal.pone.0108098

[26] Yang, K., Xun, P., Carnethon, M., Carson, A.P., Lu, L., Zhu, J. and He, K. (2019) Low to Moderate Toenail Arsenic Levels in Young Adulthood and Incidence of Diabetes Later in Life: Findings from the CARDIA Trace Element Study. Environmental Research, 171, 321-327. https://doi.org/10.1016/j.envres.2019.01.035

[27] Karim, M.R., Rahman, M., Islam, K., Mamun, A.A., Hossain, S., Hossain, E., Aziz, A., Yeasmin, F., Agarwal, S., Hossain, M.I., Saud, Z.A., Nikkon, F., Hossain, M., Mandal, A., Jenkins, R.O., Haris, P.I., Miyataka, H., Himeno, S. and Hossain, K. 
(2013) Increases in Oxidized Low-Density Lipoprotein and Other Inflammatory and Adhesion Molecules with a Concomitant Decrease in High-Density Lipoprotein in the Individuals Exposed to Arsenic in Bangladesh. Toxicological Sciences, 135, 17-25. https://doi.org/10.1093/toxsci/kft130

[28] Hoffmann, T., Warmbold, B., Smits, S., Tschapek, B., Ronzheimer, S., Bashir, A., Chen, C., Rolbetzki, A., Pittelkow, M., Jebbar, M., Seubert, A., Schmitt, L. and Bremer, E. (2018) Arsenobetaine: An Ecophysiologically Important Organoarsenical Confers Cytoprotection against Osmotic Stress and Growth Temperature Extremes. Environmental Microbiology, 20, 305-323. https://doi.org/10.1111/1462-2920.13999

[29] Navas-Acien, A., Francesconi, K.A., Silbergeld, E.K. and Guallar, E. (2011) Seafood Intake and Urine Concentrations of Total Arsenic, Dimethylarsinate and Arsenobetaine in the US Population. Environmental Research, 111, 110-118.

https://doi.org/10.1016/j.envres.2010.10.009

[30] Xiang, S., Jin, Q., Xu, F., Yao, Y., Liang, W., Zuo, X., Ye, T. and Ying, C. (2019) High Serum Arsenic and Cardiovascular Risk Factors in Patients Undergoing Continuous Ambulatory Peritoneal Dialysis. Journal of Trace Elements in Medicine and Biology, 52, 1-5. https://doi.org/10.1016/j.jtemb.2018.11.002

[31] Moon, K., Guallar, E. and Navas-Acien, A. (2012) Arsenic Exposure and Cardiovascular Disease: An Updated Systematic Review. Current Atherosclerosis Reports, 14, 542-555. https://doi.org/10.1007/s11883-012-0280-x

[32] Chen, Y., Graziano, J.H., Parvez, F., Liu, M., Slavkovich, V., Kalra, T., Argos, M., Islam, T., Ahmed, A., Rakibuz-Zaman, M., Hasan, R., Sarwar, G., Levy, D., van Geen, A. and Ahsan, H. (2011) Arsenic Exposure from Drinking Water and Mortality from Cardiovascular Disease in Bangladesh: Prospective Cohort Study. BMJ, 342, d2431. https://doi.org/10.1136/bmj.d2431

[33] Sirivarasai, J., Wananukul, W., Kaojarern, S., Chanprasertyothin, S., Thongmung, N., Ratanachaiwong, W., Sura, T. and Sritara, P. (2013) Association between Inflammatory Marker, Environmental Lead Exposure, and Glutathione S-Transferase Gene. BioMed Research International, 2013, Article ID: 474963. https://doi.org/10.1155/2013/474963

[34] Lin, C.Y., Huang, P.C., Wu, C., Sung, F.C. and Su, T.C. (2020) Association between Urine Lead Levels and Cardiovascular Disease Risk Factors, Carotid Intima-Media Thickness and Metabolic Syndrome in Adolescents and Young Adults. International Journal of Hygiene and Environmental Health, 223, 248-255. https://doi.org/10.1016/j.ijheh.2019.08.005

[35] Pollack, A.Z., Mumford, S.L., Sjaarda, L., Perkins, N.J., Malik, F., WactawskiWende, J. and Schisterman, E.F. (2017) Blood Lead, Cadmium and Mercury in Relation to Homocysteine and C-Reactive Protein in Women of Reproductive Age: A Panel Study. Environmental Health, 16, 84. https://doi.org/10.1186/s12940-017-0293-6 